\title{
One Health in Nepal- An Overview
}

Abishkar Khatiwada, ${ }^{1}$ Alina Karna, ${ }^{2}$ Neeti Bhat, ${ }^{3}$ Satish Deo ${ }^{4}$

${ }^{1-4}$ Madan Bhandari Academy of Health Sciences, Hetauda, Nepal.

In order to meet today's complex health and environmental challenges, multi-disciplinary research has never been more exigent. Nepal is in the early stages of adopting One Health $(\mathrm{OH})$, but it is continuously expanding. Various initiatives have been taken by the Government of Nepal (GoN) to combat problems such as antimicrobial resistance, highly pathogenic avian influenza and rabies using an integrated health approach, but several challenges remain in their implementation. A few of the major obstacles to implementing $\mathrm{OH}$ in Nepal include weak organizational structure to support the initiative, no legal framework required to implement $\mathrm{OH}$, insufficient technical expertise, lack of intersectoral data sharing mechanisms, a limited budget, and poor legislative understanding. To address these gaps and prioritize the health problems where $\mathrm{OH}$ will lead to the best outcome, we encourage GoN to address the gaps. To control the ongoing COVID-19 pandemic, the rational application of the One Health strategy should be our utmost priority. The One Health paradigm can help healthcare professionals and researchers improve the public's health in response to the coming wave of COVID-19 pandemic and prepare for future pandemics.

Keywords: COVID-19; Nepal; one health; pandemics

Submitted: June 15, 2021 Accepted: June 23, 2021 Published: June 28, 2021

\section{INTRODUCTION}

'One health' refers to the recognition of the inextricable links between human health, animals, plants and their shared environment. ${ }^{1}$ Collaboration, cross-sectoral thinking, and trans-disciplinary approaches are hallmarks of One Health - on the local, regional, national, and international levels. In order to achieve optimal health for people, animals, and the environment, One Health $(\mathrm{OH})$ is the most cost-effective, sustainable, and practical approach available. ${ }^{2}$ By working collaboratively in health outcomes, animal well-being, and environmental resilience it seeks to "educate" and to "create" networks for a healthier future for humans, animals, and the environment. Potential global diseases like COVID-19, highly pathogenic avian influenza (HPAI), severe acute respiratory syndrome (SARS), Middle Eastern respiratory syndrome (MERS), Hanta, Ebola, West Nile, Rift Valley fever, Norovirus, Marburg, influenza A [H1N1] and bacterial (e.g., Escherichia coli O157:H7, Yersinia pestis, and Bacillus anthracis, the causes of hemolytic uremic syndrome, plague, and anthrax, respectively) have provided serious impetus for international advocacy and funding to promote collaboration between the health, animal health, and environmental sectors[H1] .3,4 To promote $\mathrm{OH}$ in Nepal, in addition to well-funded government projects like Avian Influenza Control Project (AICP) and Zoonotic Disease Control Project (ZCP), a number of initiatives have been taken with philanthropic funding. Recently to solve the Anti-Microbial Resistance (AMR) problem in Nepal, the Government of Nepal has adopted one health-oriented approach. ${ }^{4}$

\section{An overview of the current scenario and the possibilities for one health:}

There is no separate institutional framework for the implementation of $\mathrm{OH}$ in Nepal, despite several efforts to promote $\mathrm{OH}$ in Nepal. This concept has been pushed by the World Organization for Animal Health (OIE), World Health Organization (WHO) and Food and Agriculture Organization (FAO) since early 2000.

Citation: Khatiwada A, Karna A, Bhat N, Deo S. One health as a concept. Nepal J Health Sci. 2021 Jan-Jun;1(1): 73-74 
The Ministry of Health and Population (MoHP) and Ministry of Agriculture and Livestock Development (MoALD) and their respective departments, Department of Health Services and Department of Livestock Services, lead the human and animal health sectors, respectively. Health-related issues like avian influenza, anthrax, rabies, food borne outbreaks, and a global increase in AMR are vitally important. One Health in Nepal has an opportunity to make a significant contribution since these problems require multi-sectoral engagement to effectively contain. HPAI and AMR are recent $\mathrm{OH}$ initiatives that have created platforms to advance $\mathrm{OH}$ initiatives in Nepal. ${ }^{5}$

\section{Current CHallenges:}

One Health does not get the attention it deserves due to the sectors having their own priorities. $\mathrm{OH}$ is hampered by the lack of separate institutional structures to guide its operations. There are not enough policies for intersectoral collaboration, nor is there enough coordination among stakeholders. ${ }^{6}$ It is imperative to develop a clear strategy so that $\mathrm{OH}$ can be taken forward more effectively. A "One Health Strategic Framework for Nepal" is being drafted by MoALD in collaboration with MoHP. Due to the growing number of health challenges of multidisciplinary nature, there is a need for an independent institutional framework for $\mathrm{OH}$ initiatives in Nepal. Globally, the COVID19 pandemic has damaged the world economy and continues to endanger lives. Our current health care system has been plagued by ignorance of the One Health principles. Nations around the world enforce social distancing, lockdowns, and hand hygiene as short-term preventive measures, but these can be difficult to sustain on a long-term basis. As a result, we must change our unidimensional approach to disease prevention and control. To control the ongoing dire situation, the rational application of the One Health strategy should be our utmost priority.

\section{SUMMARY:}

One Health isn't practiced in Nepal well and a few diseases have gaps in implementation and co-ordination. The main reason is the absence of institutional and legal structure to provide support for $\mathrm{OH}$. A legal and institutional framework should be set up by involving all relevant stakeholders, and an interdisciplinary organization should be established to promote one health and conquer several illnesses in Nepal. The One Health paradigm can help healthcare professionals and researchers improve the public's health in response to the COVID-19 pandemic and prepare for future pandemics.

\section{REFERENCE}

1. Acharya KP, Karki S, Shrestha K, Kaphle K. One health approach in Nepal: Scope, opportunities and challenges. One Health. 2019 Aug 12;8:100101. doi: 10.1016/j.onehlt.2019.100101. PMID: 31485475; PMCID: PMC6715885

2. Essack SY. Environment: the neglected component of the One Health triad. Lancet Planet Health. 2018 Jun;2(6):e238-e239. doi: 10.1016/S2542-5196(18)30124-4. PMID: 29880152; PMCID: PMC7129022.

3. Gibbs EP. The evolution of One Health: a decade of progress and challenges for the future. Vet Rec. 2014 Jan 25;174(4):85-91. doi: 10.1136/vr.g143. PMID: 24464377.

4. Gebreyes WA, Dupouy-Camet J, Newport MJ, Oliveira CJB, Schlesinger LS, Saif YM, et al. The Global One Health Paradigm: Challenges and Opportunities for Tackling Infectious Diseases at the Human, Animal, and Environment Interface in Low-Resource Settings. PLoS Negl Trop Dis. 2014 Nov 13;8(11):e3257. https://doi.org/10.1371/journal.pntd.ooo3257

5. Dahal R, Upadhyay A, Ewald B. One Health in South Asia and its challenges in implementation from stakeholder perspective. Vet Rec. 2017 Dec;181(23):626. doi: 10.1136/vr.104189. Epub 2017 Oct 30. PMID: 29084821.

6. Lee H, Yoon EJ, Kim D, Jeong SH, Won EJ, Shin JH, et. al. Antimicrobial resistance of major clinical pathogens in South Korea, May 2016 to April 2017: first one-year report from Kor-GLASS. Euro Surveill. 2018 Oct;23(42):1800047. doi: 10.2807/1560-7917.ES.2018.23.42.1800047. PMID: 30352640; PMCID: PMC6199864.

7. Fermet-Quinet E, Hunt T, Stratton J. PVS gap analysis report: Vietnam. Paris Fr World Organ Anim Health. 2010; page 23-25. 